\title{
3D Progressive Failure Modeling of Drop-Weight Impact on Composite Laminates
}

Dinh Chi Pham, Jim Lua, and Dianyun Zhang

\begin{abstract}
Composite laminates are susceptible to out-of-plane impact loads due to the lack of reinforcement in the through-thickness direction. Unlike the localized damage induced by a high velocity impact where the incident energy is dissipated near a contact area, low velocity impact damage involves multiple failure mechanisms such as matrix cracking, fiber breakage, and widespread interface delaminations. Depending on the extent of damage, significant reduction in the load-bearing capability of the structure has been observed. The prediction of composite impact damage resistance by a reliable progressive damage analysis tool is essential to reduce intensive and expensive certification tests at structural level. In this work, an enhanced explicit 3D damage model is implemented via VUMAT in Abaqus to perform a dropweight impact simulation of a $\left[45_{4} / 0_{4} /-45_{4} / 90_{4}\right]_{s}$ Hexply AS4/8552 composite laminate. The impact-induced damage and its extent are captured by a 3D Continuum Damage Model (CDM) coupled with an energy driven failure mechanism. The developed module provides a unified solution process for the impact response prediction followed by the residual strength prediction under compression within an explicit solver. Two examples are selected to demonstrate the capability of the progressive failure analysis under dynamic and static loading: 1) a drop-weight test; and 2) an open-hole tension test. Numerical predictions from the developed VUMAT are compared with the test data and predictions using the open source CompDam code developed by NASA.
\end{abstract}

Dinh Chi Pham and Jim Lua, Global Engineering and Materials, Inc., 1 Airport Place, Princeton, NJ 08540, USA.

Dianyun Zhang, Department of Mechanical Engineering, University of Connecticut, 191 Auditorium Road, Unit 3139, Storrs, CT 06269-3139, USA. 


\section{INTRODUCTION}

Laminated composite materials are vulnerable to out-of-plane impact loads. Different failure mechanisms in composites can manifest under impact including various types of intra-ply and inter-ply damage [1-4]. In addition, the onset and growth of these failure modes depend on various impact parameters such as the properties of an impactor, impact energies, composite layup, structural configuration or environmental conditions $[4,5]$. Low velocity impact often induces damage that is less than the Barely Visible Impact Damage (BDIV). The undetectable impact damage in terms of matrix cracking, delamination, and fiber breakage can result in a significant reduction in its compressive residual strength [6]. Therefore, understanding the impact behavior and the associated impact-induced damage in composite is crucial. Highfidelity numerical tools can effectively serve as a virtual tests for impact analysis, and assistance in reduction of the testing matrix.

Different approaches have been used to model the low velocity impact on laminated composite at the meso-scale considering the homogenized composite plies and interface delaminations [6-13]. Gonzalez et al. [6] carried out drop weight impact tests and compression after impact on composite laminates and simulated the tests using a Continuum Damage Mechanics (CDM) approach. The CDM model was based on LaRC04 failure criteria which neglects the out-of-plane stress. Donadon et al. [7] presented an explicit LS-DYNA progressive model based on the maximum strain criteria for fiber tension and compression, matrix tension and in-plane/out-of-plane shear modes to characterize composite laminate under impact loading. Bouvet et al. [8] modeled matrix cracking using the zero-thickness interface elements and accounted for permanent indentation after impact by considering the plasticity of cracked matrix. Aymerich et al. [9] predicted the impact-induced delamination in cross-ply laminate using interface cohesive elements. The cohesive elements were implemented as user material subroutine (VUMAT) in Abaqus and a damage criterion was employed to include the out-of-plane compression effects on the delamination initiation prediction. Feng et al. [10] extended the work [9] by incorporating constitutive models for intralaminar damage and interlaminar damage in VUMAT and obtained good correlation with the experiment results for drop-weight impact. In the earlier work of Zhang et al. [11], potential delamination and matrix cracking areas were characterized by cohesive zones with the damage evolution associated with contacting interfaces. The damage model was implemented as a user subroutine VUINTER and provided a good prediction for the low velocity impact damage of composite structures. Despite extensive work has been done on characterization of impact damage and performance of failure prediction, it has been a continuous interest to explore an efficient and accurate progressive damage analysis (PDA) tool for simulation of impact response and performance of residual strength prediction after an impact event. Modeling challenges exist to achieve a convergent solution with less demanding on the computer resource.

In this work, an explicit 3D damage model was enhanced and implemented as VUMAT for Abaqus to simulate the impact response of a composite component. The maximum stress failure criteria are used to predict intra-ply damage initiation and an energy driven mode is applied for damage progression. The use of the explicit solver can enhance the solution convergence and the enhanced VUMAT provides an efficient solution for static failure analysis. In addition to the CDM based intra-ply 
damage description, a cohesive element based inter-ply damage characterization is also applied at each ply interface. The drop-weight impact on $\left[45_{4} / 0_{4} /-45_{4} / 90_{4}\right]_{\mathrm{s}}$ Hexply AS4/8552 composite laminate is selected for the capability demonstration. Simulation results are compared with the impact tests performed by Gonzalez et al. [6] and results from the open source CompDam code [14]. To further demonstrate the applicability of the developed VUMAT for the static failure analysis, an open-hole tension case was re-visited and the prediction was compared with Tech Scout 1 test data [19] and simulation results using CompDam.

\section{METHODOLOGY OVERVIEW}

An orthotropic constitutive material model for damage initiation and progression is implemented in Abaqus via its VUMAT. In this study, the maximum stress failure criteria are employed for the intra-ply damage. The maximum stress criteria fully consider the 3D stress state and allow modeling of different fiber and matrix failure modes separately under impact. The corresponding equations for matrix and fiber failure under tension, compression and shear are presented as follows where 1 and 2 are the longitudinal and transverse directions, respectively, and 3 is the throughthickness direction:

In-plane and out-of-plane shear failure:

$$
\left\{\begin{array}{l}
\left|\sigma_{12}\right| \geq S_{12} \\
\left|\sigma_{13}\right| \geq S_{13} \\
\left|\sigma_{23}\right| \geq S_{23}
\end{array}\right.
$$

Tensile and compressive fiber failure:

$$
\left\{\begin{array}{l}
\sigma_{11 T} \geq X_{T} \\
\left|\sigma_{11 C}\right| \geq X_{C}
\end{array}\right.
$$

Tensile and compressive matrix failure:

$$
\left\{\begin{array}{l}
\sigma_{22 T} \geq Y_{T} \\
\left|\sigma_{22 C}\right| \geq Y_{C}
\end{array}\right.
$$

Tensile and compressive out-of-plane failure:

$$
\left\{\begin{array}{l}
\sigma_{33} \geq Z_{T} \\
\left|\sigma_{33 C}\right| \geq Z_{C}
\end{array}\right.
$$

In the above equations $\sigma_{12}, \sigma_{13}, \sigma_{23}$ are the computed shear stress components and $\sigma_{11}, \sigma_{22}, \sigma_{33}$ are the computed normal stresses components along the fiber direction, transverse-to fiber direction and through-the-thickness direction, 
respectively; $X_{T}, X_{C}, Y_{T}, Y_{C}, Z_{T}, Z_{C}$ are the longitudinal tensile and compressive strengths, transverse tensile and compressive strengths, and out-of-plane tensile and compressive strengths, respectively.

Once matrix or fiber damage is initiated at a material point, the damage evolution is characterized by a crack band approach with a given fracture energy. In the crack band approach, it is assumed that distributed cracks are smeared out over a certain width within a finite element such that the effect of progressive cracking is represented by macroscopic strain softening in a continuum scheme. To restore mesh objectivity, a characteristic length is introduced such that the total amount of energy dissipated during failure in a continuum element is equal to the fracture toughness (or the Critical Strain Energy Release Rate, SERR) defined for a cohesive element of the same size $[15,16]$. For composites, the crack band approach assumes that the crack evolution under each failure mode is governed by SERR in the respective mode [1518]. Different from the existing approach based on a 2D stress state, a full 3D stress state is considered to determine the failure initiation. For an element of its characteristic length of $L^{c}$, the energy dissipation due to each matrix and fiber failure mode is dictated by the corresponding SERR $G_{c}^{f}$ of fiber and $G_{c}^{m}$ of the matrix as:

$$
\int \sigma_{i j} d\left(\varepsilon_{i j} L^{c}\right)=G_{c}^{f / m}
$$

Unlike the intra-ply damage prediction described above, inter-ply delamination is characterized using an existing Abaqus' cohesive element based on a mixed mode traction-separation law. Delamination onset is assumed to follow a quadratic failure criterion:

$$
\frac{\left\langle\sigma_{n}\right\rangle^{2}}{N^{2}}+\frac{\sigma_{s}^{2}}{S^{2}}+\frac{\sigma_{t}^{2}}{T^{2}}=1
$$

where $\sigma_{n}, \sigma_{s}, \sigma_{t}$ are the normal and two shear tractions and $N, S, T$ are the corresponding normal and shear interfacial strength. For mixed mode delamination, equivalent traction $T_{e q}$ and displacement $\delta_{e q v}^{\text {int }}$ are introduced, and delamination propagation is indicated by a mixed-mode energy Benzeggagh and Kenane law:

$$
\begin{aligned}
& G_{e q c}=G_{I c}^{\mathrm{int}}+\left(G_{I I c}^{\mathrm{int}}-G_{I c}^{\mathrm{int}}\right)\left(\frac{G_{I I}+G_{I I I}}{G_{I}+G_{I I}+G_{I I I}}\right)^{\eta} \\
& \int T_{e q} d \delta_{e q v}^{\mathrm{int}}=G_{e q c}
\end{aligned}
$$

The damage prediction by our developed CDM model is compared with the prediction by CompDam [14]. CompDam is an Abaqus/Explicit user material (VUMAT) subroutine by NASA. A key feature of CompDam is its ability to accurately represent matrix crack kinematics according to the deformation gradient decomposition method. 


\section{SIMULATIONS AND RESULTS}

\section{Simulation of drop-weight impact test on Hexply AS4/8552 laminate}

Drop-weight impact on a laminated composite plate made of Hexply AS4/8552 is simulated to demonstrate the capability and accuracy of the developed explicit CDM module. The composite plate has a layup of $\left[45_{4} / 0_{4} /-45_{4} / 90_{4}\right]_{\mathrm{s}}$ and a dimension of 150 x $100 \times 5.8 \mathrm{~mm}^{3}$. Each ply of composite plate is explicitly modeled by threedimensional solid elements (C3D8R) while the interfaces between individual plies are characterized using Abaqus cohesive elements (COH3D8). The impactor is described as a rigid body (R3D4) with a diameter of $16 \mathrm{~mm}$. Four rubber-tipped rigid clamps (R3D4) are used to constrain the specimen with the base support. Contacts are enforced between the plate with the impactor, with the rigid clamps and the fixture base. A friction coefficient of 0.3 is defined for the contact between the composite material and the steel impactor. The FE model of the $\left[45_{4} / 0_{4} /-45_{4} / 90_{4}\right]_{s}$ composite plate along with the impactor is shown in Figure 1. The Hexply AS4/8552 properties and the interface properties are reported in Table I and II. One-step analysis including the initial clamping and impact simulation is carried out using the explicit solver of Abaqus. The results by our 3D CDM are compared to the testing data by Gonzalez et al. [6] and benchmarked against the open source code CompDam [14].

Figure 2 shows an example of through-the-thickness cut view of the $\left[45_{4} / 0_{4} /-\right.$ $\left.454 / 90_{4}\right]_{s}$ AS4/85520 laminate and its damage prediction under $38.6 \mathrm{~J}$ impact energy. It can be seen from Figure 2 that the initial matrix compressive and shear failure due to the out-of-plane stress components are predicted, followed by additional matrix tensile and shear failure caused by in-plane stresses. Figure $3 \mathrm{a}$ and $3 \mathrm{~b}$ show the comparisons on the matrix damage prediction between our 3D CDM and CompDam for the same impact energy. It is observed that the CompDam predicts more matrix damage in through-the-thickness direction than our 3D CDM but less damage around the contact area with the impactor. Figure $3 \mathrm{c}$ plots the impact force vs time history curves by the two codes in comparison with the drop-weight impact experimental results [6]. It can be shown that the global force-time response of the composite plate is correctly predicted by our CDM model. Although the CompDam code well captures the behavior of the plate at the early stage of the impact event, it over-predicts the experimental peak load whereas our CDM prediction agrees better with the measured peak load.

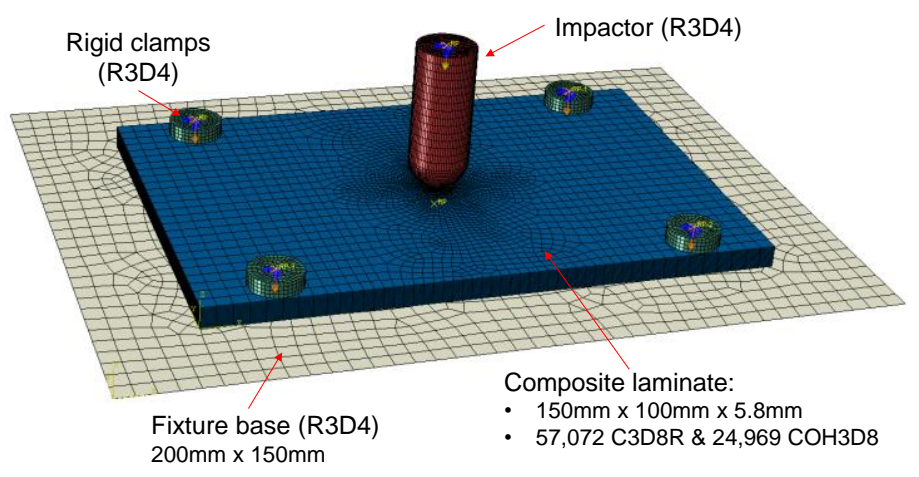

Figure 1. FE model of the impact test 
TABLE I. HEXPLY AS4/8552 PROPERTIES [6]

\begin{tabular}{ccccc}
\hline $\boldsymbol{E}_{11}$ & $\boldsymbol{E}_{22}=\boldsymbol{E}_{33}$ & $\boldsymbol{G}_{12}=\boldsymbol{G}_{13}$ & $\boldsymbol{v}_{12}=\boldsymbol{v}_{13}$ & $\boldsymbol{v}_{23}$ \\
$128 \mathrm{GPa}$ & $7.63 \mathrm{GPa}$ & $4.36 \mathrm{GPa}$ & 0.32 & 0.436 \\
$\boldsymbol{X}_{\boldsymbol{t}}$ & $\boldsymbol{X}_{\boldsymbol{c}}$ & $\boldsymbol{Y}_{\boldsymbol{t}}$ & $\boldsymbol{Y}_{\boldsymbol{c}}$ & $\boldsymbol{S}_{\boldsymbol{1 2}}$ \\
$2300 \mathrm{MPa}$ & $1531 \mathrm{MPa}$ & $26 \mathrm{MPa}$ & $199.8 \mathrm{MPa}$ & $78.4 \mathrm{MPa}$ \\
$\boldsymbol{G}_{I c+}^{f}$ & $G_{I c-}^{f}$ & $G_{I c}^{m}$ & $G_{I I c}^{m}$ & \\
$81.5 \mathrm{~kJ} / \mathrm{m}^{2}$ & $106.3 \mathrm{~kJ} / \mathrm{m}^{2}$ & $0.21 \mathrm{~kJ} / \mathrm{m}^{2}$ & $0.77 \mathrm{~kJ} / \mathrm{m}^{2}$ & \\
\hline
\end{tabular}

TABLE II. HEXPLY AS4/8552 INTERFACE PROPERTIES [6]

\begin{tabular}{cclc}
\hline$N$ & $S=\boldsymbol{T}$ & $G_{I c}^{\text {int }}$ & $G_{I I c}^{\text {int }}=G_{I I I c}^{\text {int }}$ \\
$60 \mathrm{MPa}$ & $90 \mathrm{MPa}$ & $0.21 \mathrm{~kJ} / \mathrm{m}^{216}$ & $0.77 \mathrm{~kJ} / \mathrm{m}^{216}$ \\
\hline
\end{tabular}
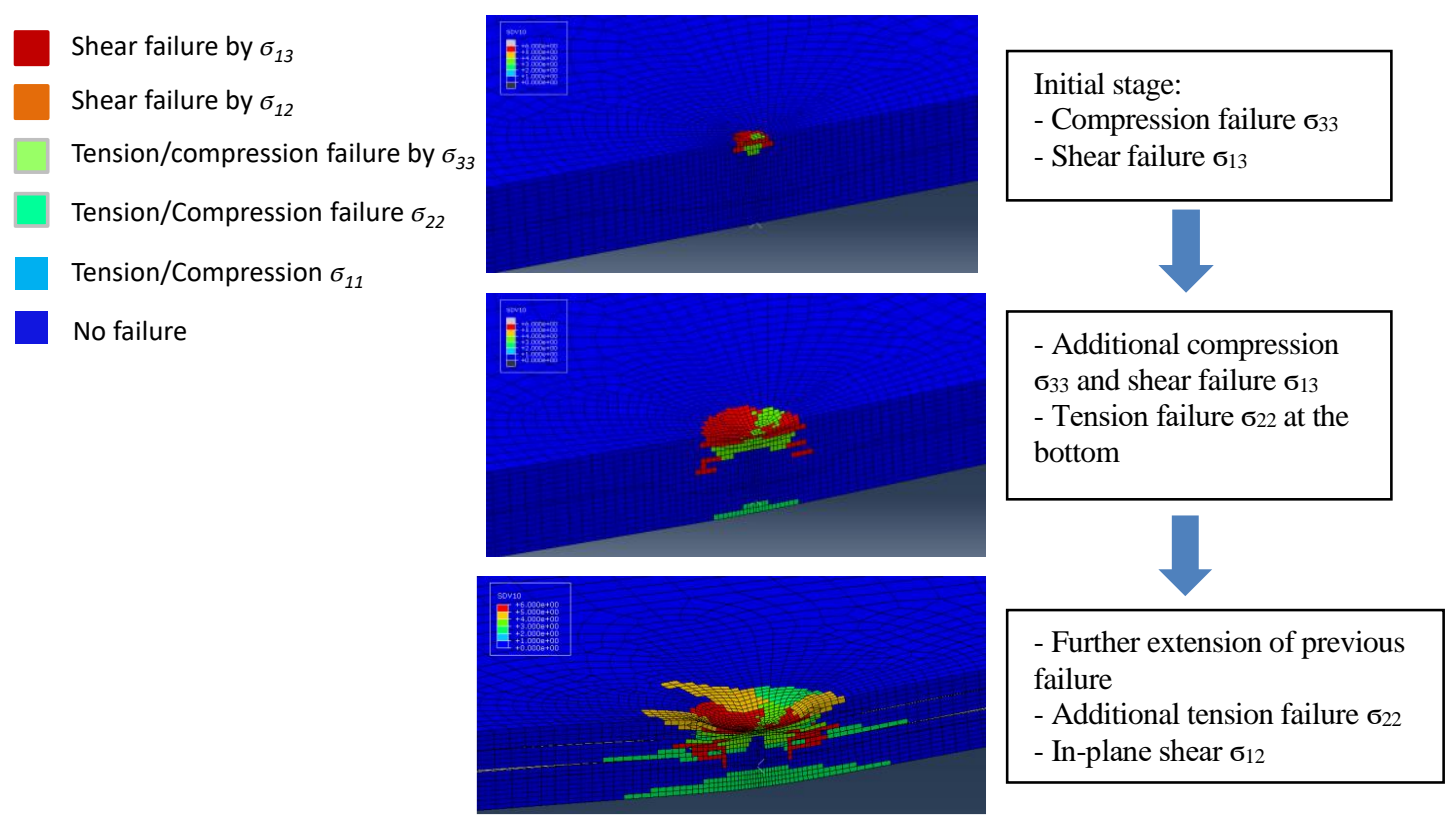

(a)

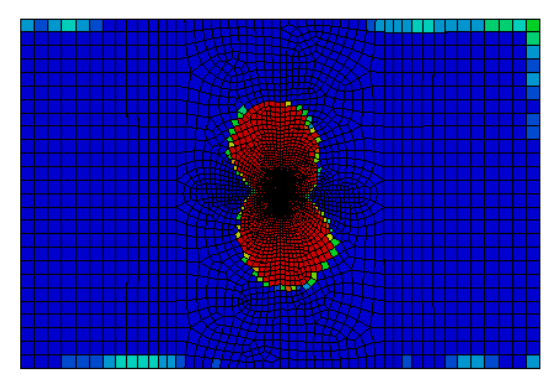

(b)

Figure 2. Predicted damage progression in $\left[45_{4} / 0_{4} / 45_{4} / 90_{4}\right]_{\mathrm{S}}$ AS4/8552 laminate for $38.6 \mathrm{~J}$ by the developed CDM (a) and predicted delamination at the [45/0] interface (b) 


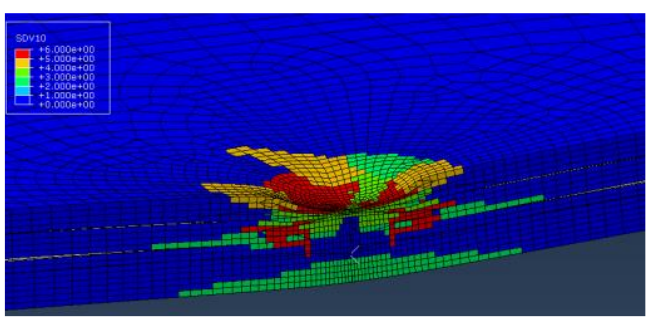

(a)

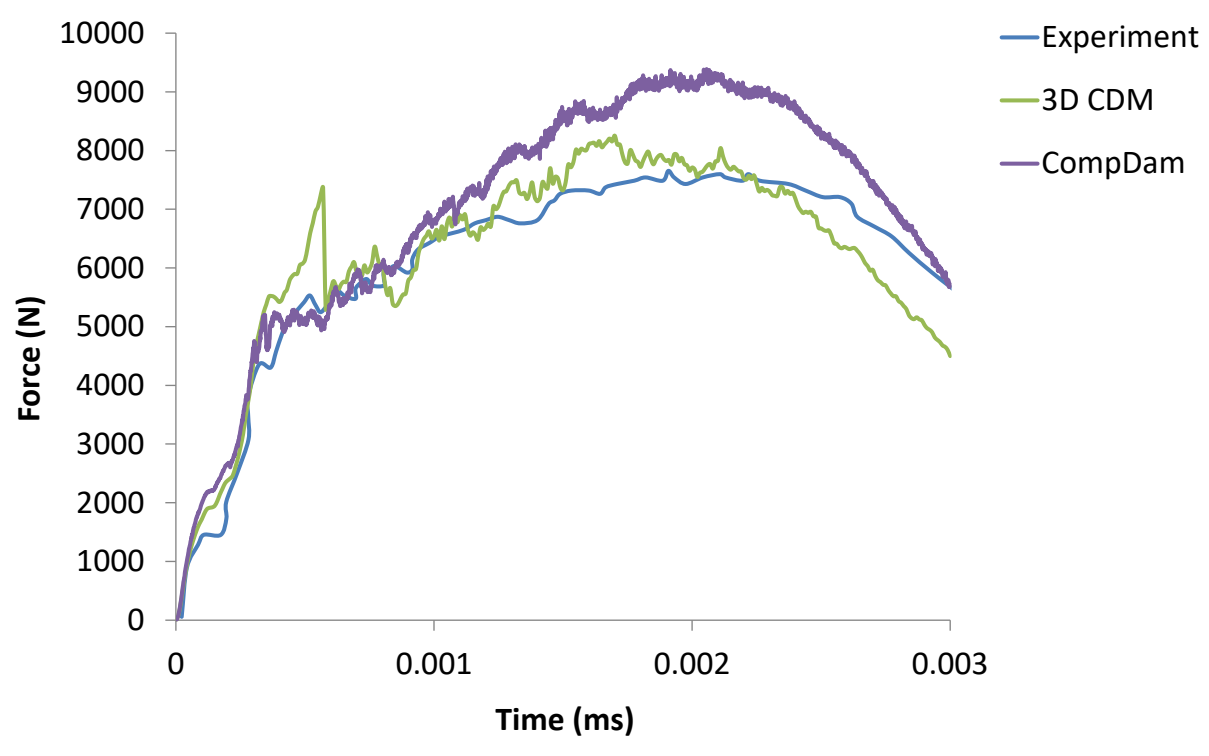

(c)

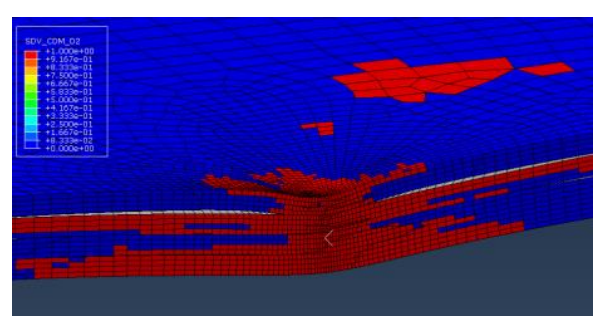

b)

-Experiment

-3D CDM

CompDam

Figure 3. Predicted impact damage by our CDM (a), ComDamp [14] (b) and comparison on the predicted impact force history curves of the $\left[45_{4} / 0_{4} / 45_{4} / 90_{4}\right]_{S}$ AS4/8552 laminate for $38.6 \mathrm{~J}$ with the experimental data from Gonzalez et al. [6] (c)

\section{Simulation of open-hole tension specimen}

The developed 3D CDM model is further verified for the in-plane loading case using an open hole tension (OHT) specimen. This test is designed to examine the capability of the developed VUMAT for the static failure prediction using Abaqus explicit solver. The composite plate has a [60/0/-60] $]_{3 \text { s }}$ layup and made of a generic carbon-fiber-reinforced epoxy tape. The material properties are summarized in Table III. The laminate has a dimension of $138 \times 38.1 \times 2.3 \mathrm{~mm}^{3}$ with clamped edges subjected to tension at one end while the other end is fixed. Figure 4 shows the FE model of the OHT specimen. Each ply of the plate is modeled with solid elements (C3D8R) while cohesive elements are introduced to each ply interface for delamination modeling. Our developed 3D CDM and CompDam [14] are employed to predict the damage initiation and propagation in the $[60 / 0 /-60]_{3 \mathrm{~s}}$ OHT plate.

Figure 5 and 6 shows the predicted matrix damage in individual plies of the OHT plate by our 3D CDM and CompDam in comparison with the scanning test data, respectively. It can be observed that the predicted matrix damage is mainly found in 
the $\pm 60^{\circ}$ plies initiating from the notch. Damage predictions by the two codes are consistent and agree well with the scanning test data. Furthermore, Figure 7 plots the predicted stress-strain curves by the 3D CDM, CompDam and the test data. It is found that the failure stress prediction of the OHT by the 3D CDM is slightly higher than CompDam. The predicted peak stress of the OHT specimen by our 3D CDM is 478 $\mathrm{MPa}$, which is about $88 \%$ of the failure load obtained from the test [19]. The discrepancy between the prediction and experiment may be attributed to the low value of the transverse tensile strength $\left(Y_{t}=44.4 \mathrm{MPa}\right)$ used in our CDM model which is lower than the true property of the material.

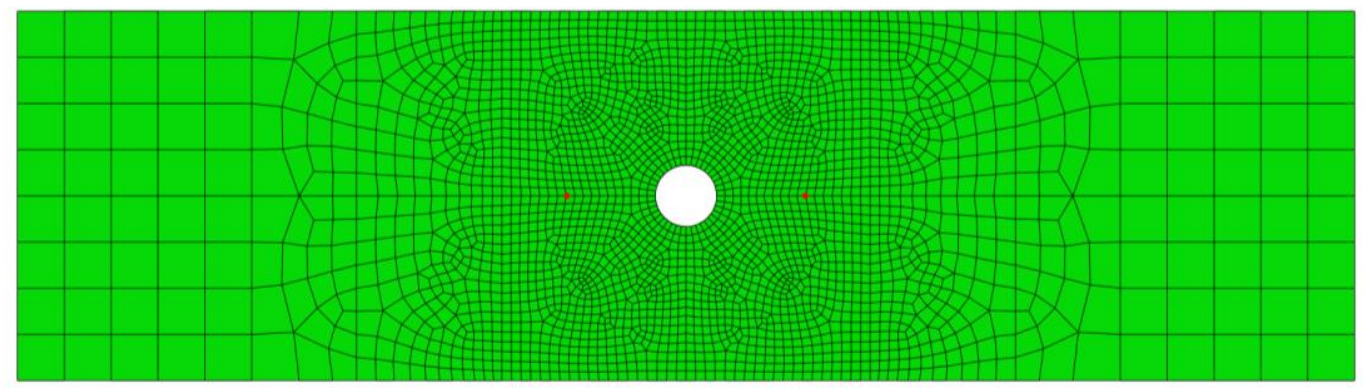

Figure 4. FE model of the open hole tension plate with [60/0/-60] $]_{3 s}$ layup

\begin{tabular}{ccccc} 
TABLE III. PROPERTIES OF A GENERIC CARBON-FIBER-REINFORCED EPOXY TYPE \\
\cline { 1 - 5 } & $\boldsymbol{E}_{22}=\boldsymbol{E}_{33}$ & $\boldsymbol{G}_{12}=\boldsymbol{G}_{13}$ & $\boldsymbol{v}_{\boldsymbol{1 2}}=\boldsymbol{v}_{13}$ & $\boldsymbol{v}_{23}$ \\
$164.3 \mathrm{GPa}$ & $8.977 \mathrm{GPa}$ & $5.012 \mathrm{GPa}$ & 0.32 & 0.44 \\
$\boldsymbol{X}_{\boldsymbol{t}}$ & $\boldsymbol{X}_{\boldsymbol{c}}$ & $\boldsymbol{Y}_{\boldsymbol{t}}$ & $\boldsymbol{Y}_{\boldsymbol{c}}$ & $\boldsymbol{S}_{\boldsymbol{1}}$ \\
$2905 \mathrm{MPa}$ & $1274 \mathrm{MPa}$ & $44.4 \mathrm{MPa}$ & $247.6 \mathrm{MPa}$ & 80.44 \\
& & & & $\mathrm{MPa}$ \\
$G_{I c+}^{f}$ & $G_{I c-}^{f}$ & $G_{I c}^{m}$ & $G_{I c}^{m}$ & \\
$81.5 \mathrm{~kJ} / \mathrm{m}^{2}$ & $65 \mathrm{~kJ} / \mathrm{m}^{2}$ & $0.2959 \mathrm{~kJ} / \mathrm{m}^{2}$ & $0.6499 \mathrm{~kJ} / \mathrm{m}^{2}$ & \\
\hline
\end{tabular}



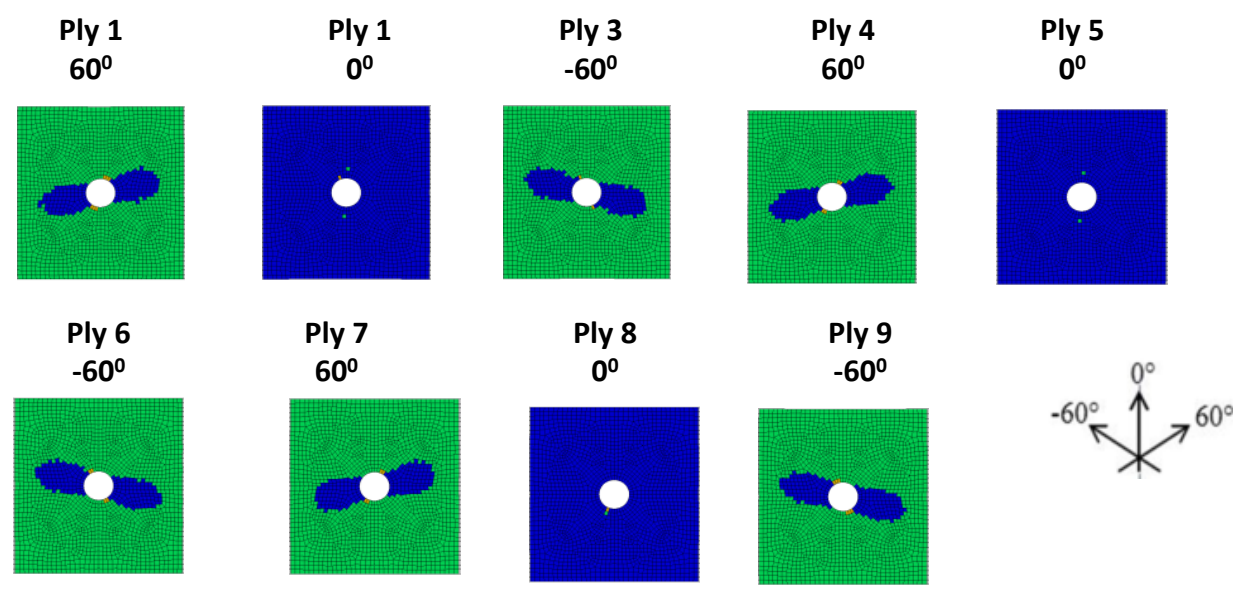

Test scan at ply boundary

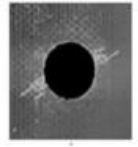

Ply 1

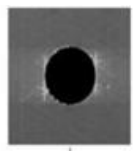

Ply 2

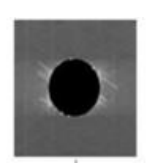

Ply 3

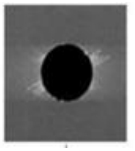

Ply 4

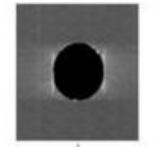

Ply 5

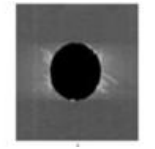

Ply 6

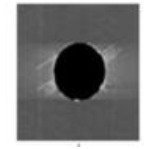

Ply 7

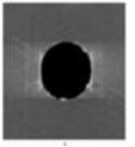

Ply 8

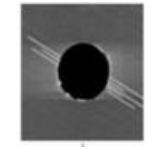

Ply 9

Figure 5. Matrix damage prediction by our 3D CDM at the peak load in comparison with test data
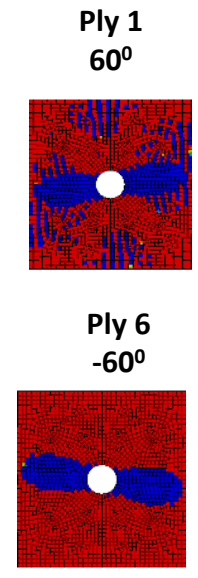

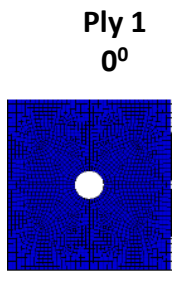

Ply 7

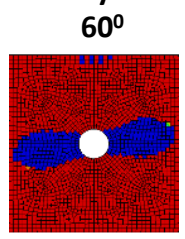

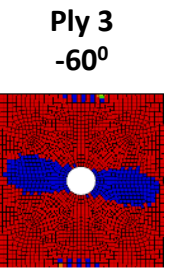

Ply 8

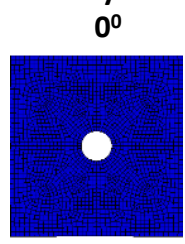

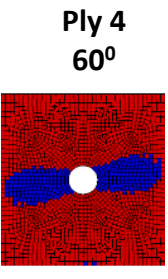

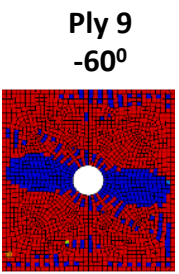

Ply 5

$0^{0}$
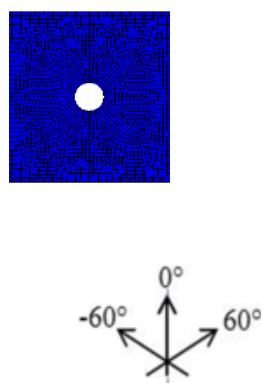

\section{Test scan at ply boundary}

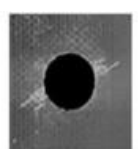

Ply 1

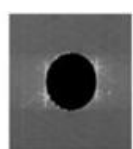

Ply 2

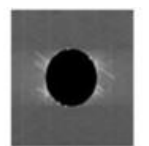

Ply 3

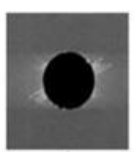

Ply 4

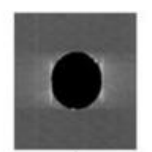

Ply 5

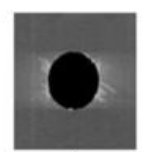

Ply 6

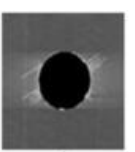

Ply 7

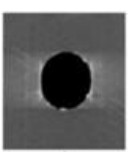

Ply 8

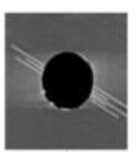

Ply 9

Figure 6. Matrix damage prediction by ComDamp [14] at the peak load in comparison with test data 


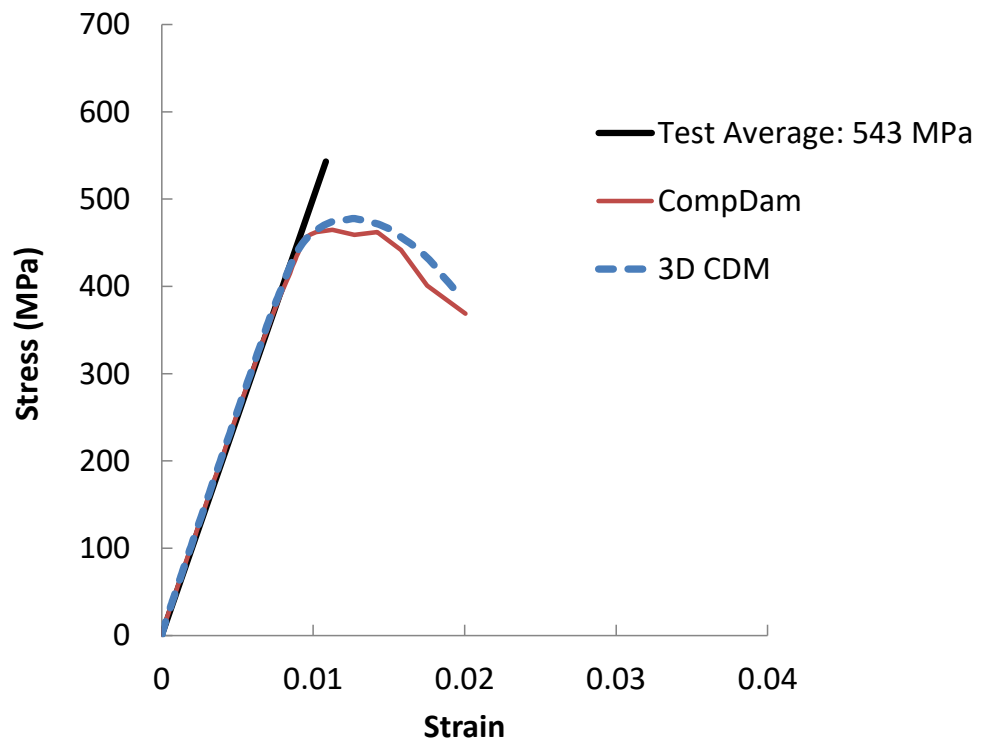

Figure 7. The predicted failure stress by our 3D CDM (a), ComDamp (b) and comparison with the average failure stress of $543 \mathrm{MPa}$ measured in the experiment.

\section{SUMMARY}

An explicit 3D progressive damage model, implemented as VUMAT for Abaqus, has been demonstrated for two test cases under dynamic and static loading. The dynamic simulation case is associated with the low velocity impact of the $\left[45_{4} / 0_{4} /-\right.$ 454/904 $]_{s}$ Hexply AS4/3501-6 composite laminate while the static case is associated with the open-hole tension test of the $[60 / 0 /-60]_{3 s}$ laminate. Matrix tensile and compressive damage, shear failure, fiber tensile and compressive damage in individual plies and interface delamination of the composite laminates have been captured by our 3D CDM for Abaqus explicit solver. Its numerical predictions have been benchmarked with the prediction by the open source CompDam code [14] and verified against the test data. Favorable agreements between the simulation and experiment are achieved, indicating the validity of our explicit 3D CDM for predicting multiple failure modes of composite plates under out-of-plane impact and in-plane loading cases. In addition to the enhanced numerical stability by using the explicit solver, the current solution framework has demonstrated its feasibility for the simulation of impact response followed by the prediction of the compressive residual strength after impact without user intervention.

\section{REFERENCES}

1. Abrate S. 1991. "Impact on laminated composite materials," Appl. Mech. Rev., 44(155)

2. Choi H.Y., Downs R.J., and Chang F-K. 1991. "A new approach toward understanding damage mechanisms and mechanics of laminated composites due to low-velocity impact: Part Iexperiments," J Compos Mater, 25:992-1011.

3. Pham D.C., Narayanaswamy S. 2015. "An effective modeling strategy for drop test analysis of composite curved beam", 56th AIAA/ASCE/AHS/ASC Structures, Structural Dynamics, and Materials Conference, 5-9 January, 2015. 
4. Topac O.T., Gozluklu B., Gurses E., Coker D. 2017. "Experimental and computational study of the damage process in CFRP composite beams under low-velocity impact," Compos. Part A - Appl. S., 92:167-182.

5. González E.V., Maimí P., Camanho P.P., Lopes C.S., and Blanco N. 2011. "Effects of ply clustering in laminated composite plates under low-velocity impact loading," Compos. Sci. Technol., 71:805-17.

6. González E.V., Maimí P., Camanho P.P., Turon A., and Mayugo J.A. 2012. "Simulation of dropweight impact and compression after impact tests on composite laminates," Compos. Struct., 94:3364-78.

7. Donadon M.V., Iannucci L., Falzon B.G., Hodgkinson J.M., and de Almeida SFM. 2008. "A progressive failure model for composite laminates subjected to low velocity impact damage," Comput. Struct. , 86(11-12):1232-52.

8. Bouvet C., Rivallant S., and Barrau J.J. 2012. "Low velocity impact modeling in composite laminates capturing permanent indentation," Compos. Sci. Technol., 72(16):1977-1988.

9. Aymerich F., Dore F., Priolo P. 2008. "Prediction of impact-induced delamination in cross-ply composite laminates using cohesive interface elements," Compos. Sci. Technol., 68(12):2383-2390.

10. Feng D., Aymerich F. 2014. "Finite element modelling of damage induced by low-velocity impact on composite laminates," Compos. Struct., 108:161-171.

11. Zhang Y., Zhu P., Lai X. 2016. "Finite element analysis of low-velocity impact damage in composite laminated plates," Mater Des, 27(6):513-9.

12. Pham D.C., Narayanaswamy S. 2014. "An Optimization Tool for Impact Analysis of Composite Structures," Procedia Eng., 74:3-8.

13. Hou J.P., Petrinic N., Ruiz C., and Hallett S.R. 2000. "Prediction of impact damage in composite plates," Compos. Sci. Technol., 60(2):273-81.

14. Leone Jr., F. A., Bergan, A. C., Davila, C. G. 2018. CompDam - Deformation Gradient Decomposition (DGD), v2.1.3, https://github.com/nasa/CompDam DGD.

15. Zhang, D., Waas, A. M., and Yen, C. F. 2015. "Progressive damage and failure response of hybrid 3D textile composites subjected to flexural loading, Part II: Mechanics based multiscale computational modeling of progressive damage and failure," Int. J. Solids Struct., 75-76, pp. 321335.

16. Zhang, D., Patel, D., and Waas, A. M. 2015.“A novel two-scale progressive failure analysis method for laminated fiber-reinforced composites," 56th AIAA/ASCE/AHS/ASC Structures, Structural Dynamics and Materials Conference, AIAA SciTech, 5-9 January, 2015, Kissimmee, Florida. AIAA 2015-0969.

17. Pham D.C., Sun X.S., Tan V.B.C., Chen B., Tay T.E. 2012. "Progressive Failure Analysis of Scaled Double-Notched Carbon/Epoxy Composite Laminates," Int. J. Damage Mech., 21(8), pp: 1154-1185.

18. Pham D.C., Sun X.S. 2012. "Experimental and computational studies on progressive failure analysis of notched cross-ply CFRP composite," Int. J. Comp. Mat. Sci. Eng., 1(3).

19. Cui X., Fang E., and Lua J. 2017. "A discrete crack network toolkit for Abaqus for damage and residual strength prediction of laminated composites," J Compos Mater, 51(10):1355-1378. 